\title{
Hannah Arendt, o Social e a Sociedade (Civil)
}

\author{
Hannah Arednt, the Social and the (Civil) Society
}

DOI: $10.20873 / \mathrm{rpv} 6 \mathrm{n} 2-01$

\section{Helton Adverse}

Orcid: 0000-0001-9455-2057 Email: heltonadverse@hotmail.com

\section{Resumo}

Este artigo tem por objetivo mostrar que a crítica de Hannah Arendt ao social, formulada sobretudo em $A$ condição humana, não deve obscurecer o fato de que sua teoria do político não apenas é compatível com a ideia de sociedade civil, mas a mobiliza em determinados contextos, o que pode ser comprovado quando retomamos seu livro sobre as revoluções e seu texto sobre a desobediência civil.

\section{Palavras-chave}

Arendt, Locke, Social, Sociedade Civil.

\begin{abstract}
This article aims to show that Hannah Arendt's "critique of the social", formulated above all in The Human Condition, should not obscure the fact that her theory of the political is not only compatible with the idea of civil society, but mobilizes it in certain contexts, which can be seen when we return to her book on revolutions and her text on civil disobedience.
\end{abstract}

\section{Keywords}

Arendt, Locke, Social, Civil Society.

Em A condição humana Arendt nos apresenta uma concepção fortemente crítica do social, fundamentada na necessidade de identificar a especificidade da esfera política. Neste contexto, entre o social e o político é estabelecida uma oposição intransponível, visto que o primeiro, prolongando o espaço privado do oikos, se apresenta como o domínio em que buscamos 
a satisfação das necessidades vitais, ao passo que o segundo corresponde ao espaço público da pólis, destinado propriamente à ação e ao exercício da liberdade. Além disso, o social, nos diz Arendt no mesmo livro, não está somente em continuidade com o espaço privado. Como um fenômeno especificamente moderno, ele excede as fronteiras do espaço privado para colocar sob a luz da esfera pública aquilo que até então permanecia recôndito ${ }^{1}$. 0 social é uma esfera "híbrida" na qual se embaralham os assuntos públicos e os privados, com a consequência política imediata de desfiguração da esfera pública, isto é, sua colonização por problemas que não lhe concernem originalmente. Em suma, o "surgimento do social" é compreendido por Arendt como o processo cujo resultado mais notável é o "encurtamento" da esfera pública e seu desvirtuamento pela introdução de preocupações de natureza não política.

Não foram poucas as críticas que Arendt recebeu por essa tentativa de distinguir e de separar as duas esferas ${ }^{2}$. No texto que se segue, não pretendo reativar esse debate. Meu objetivo é simplesmente inquirir se a visão extremamente crítica que Arendt lança sobre o social teria eclipsado um de seus aspectos, isto é, o fato de que a sociedade é também compreendida pela autora como o espaço para a associação ente indivíduos politicamente engajados, isto é, como espaço da cidadania. Sob este prisma, o termo "sociedade" parece ser mais adequado do que o termo "social" para expressar esta característica, embora Arendt não faça a distinção conceitual rigorosa entre eles ${ }^{3}$. Mas parece-me que ela prefere o termo "social" para caracterizar o fenômeno moderno do "crescimento não-natural do natural", enquanto retém "sociedade" para denotar o espaço entre o público e o privado. É fundamental para meus propósitos chamar a atenção para este aspecto porque isso abre a possibilidade de aproximar a "sociedade" do conceito

\footnotetext{
1 "Society is the form in which the fact of mutual dependence for the sake of life and nothing else assumes public significance and where the activities connected with sheer survival are permitted to appear in public" (ARENDT, 1958, p. 46).

${ }^{2}$ Na história dessa recepção crítica, duas obras se destacam: The attack of the blob. Hannah Arendt's concept of the social, de Hanna F. Pitkin (1998) e The reluctant modernism of Hannah Arendt, de Seyla Benhabib (2003). Dentre os estudiosos brasileiros, vale a pena destacar o artigo de Adriano Correia, "A Questão Social em Hannah Arendt: Apontamentos Críticos" (2008).

${ }^{3}$ Via de regra, elas os utilizam de forma equivalente, como é possível constatar nas citações da primeira nota.
} 
clássico de "sociedade civil", que acredito ser absorvido por Hannah Arendt, sem que ela o explicite.

Dizendo de outra maneira, meu objetivo é mostrar que a crítica de Arendt ao social não deve fazer esquecer que sua teoria do político não apenas é compatível com a ideia de sociedade civil, mas a mobiliza em determinados contextos. Para alcançar esse objetivo, não acredito ser preciso reconstituir sua crítica ao social, presente sobretudo em A condição humana, uma vez que é bastante conhecida. Procedimento mais proveitoso será indicar a presença dessa concepção de sociedade no trabalho posterior de Arendt, especificamente, no livro sobre a revolução e no texto sobre a desobediência civil. Na lida com esses textos, será de grande auxílio mostrar como a noção de sociedade civil adquire importância para Arendt na medida em que ela recupera certos aspectos da tradição contratualista, sobretudo em sua versão lockeana. A leitura que Arendt faz de Locke indica a mudança de sua recepção da noção de sociedade civil. E convém lembrar que nos anos 1950, quer dizer, no contexto de $A$ condição humana, o pensamento de Locke é considerado paradigmático do momento da "ascensão do social", o que significa que seria possível fazer a história desses diferentes momentos da compreensão de Arendt acerca da sociedade civil em paralelo com sua recepção do pensamento de Locke. Com efeito, a presença de Locke no livro de 1958 não pode ser negligenciada, Arendt dele se servindo para caracterizar a sociedade moderna como aquela dominada pela figura do animal laborans e por uma nova configuração do problema da propriedade (ARENDT, 1958, p. 70). Locke aparece aqui como o pensador do trabalho. Mais tarde, a partir dos anos 1960, Locke será o pensador do contrato social em sua versão "horizontal", propriamente associativa. E, nesse contexto, ele teria colocado no primeiro plano a capacidade humana de prometer e de se engajar. Mas certamente a leitura de Locke por Arendt segue em paralelo à sua apreciação da sociedade, pois não creio ser correto afirmar que uma coisa dependa da outra, como se uma nova interpretação do filósofo inglês tivesse produzido uma alteração no modo de Arendt compreender a sociedade. De meu ponto de vista, o que leva Arendt a conceder espaço para a noção de sociedade civil (mesmo que não seja assim nomeada sempre) é seu interesse pelas revoluções, o que colocou 
no centro de sua reflexão o problema dos conselhos e das comunidades políticas que se constituem sem a necessidade do Estado.

Este trabalho será dividido em três partes. Na primeira, vou esboçar uma concepção esquemática de sociedade civil, incluindo aquela de Locke. Na segunda parte, quero examinar como a história da Revolução Americana permitiu a Arendt colocar em termos diferentes o problema da sociedade, sem abrir mão de sua crítica ao social. Por fim, na terceira parte, quer chamar a atenção para a retomada do conceito de sociedade civil a propósito do fenômeno da desobediência civil.

\section{0 Conceito de Sociedade Civil}

O conceito tem raízes na Idade Média, especificamente, na discussão acerca do direito natural tal qual foi estabelecida no interior do pensamento tomista. Em linhas gerais, tratavase de restituir à vida social e política um significado que lhe havia sido retirado pela tradição cristã, a saber, aquele indicado pela continuidade entre lei divina e justiça terrena, a comunidade aparecendo como a realização da natureza humana em concordância com os imperativos religiosos ${ }^{4}$. A grande novidade representada, nesse domínio, pela filosofia tomista é a restituição, dentro dos limites impostos pela teologia cristã, da dignidade da vida social. A sociedade passa a ser compreendida como o lugar de realização da lei de natureza, o que será decisivo para a formulação do futuro conceito de sociedade civil. Essa será a intuição de base que resistirá às mudanças políticas significativas que ocorrerão nos séculos seguintes, isto é, a ideia de que a sociedade é um espaço de constituição do poder. Tanto as teorias contratualistas, que buscavam uma forma de legitimação da autoridade política, quanto as teorias do direito de resistência, que procuravam fundamentar a recusa à submissão a um governo considerado abusivo, serão devedoras, em alguma medida, dessa fonte medieval. É verdade que a noção de lei de natureza sofrerá uma profunda modificação no século XVII, como vemos em Grotius e

\footnotetext{
${ }^{4}$ No que se segue, acompanho as análises de Adam B. Seligman, em seu livro já clássico, The idea of civil society (1992).
} 
Hobbes, mas continuará sendo um recurso de grande valia para a definição do direito público (SELIGMAN, 1992, pp. 17-21). Seguramente, é em Locke que veremos a conjunção completa dessas duas vertentes desdobradas a partir do direito natural medieval, a saber, aquela do contratualismo e aquela outra do direito de resistência. A teoria lockeana restitui a ideia de uma lei de natureza, em última instância de origem divina, conjugada com o dever moral de sua realização na comunidade humana, o que delimita previamente ao estabelecimento do poder político suas limitações e o direito de sua deposição. Por esse motivo, alguns comentadores, dentre eles Jean-Fabien Spitz, acreditam ser pertinente afirmar que Locke dá um passo decisivo em direção à formulação da noção tipicamente moderna de "poder constituinte"5.

Mas gostaria de reter a ideia de base, a saber, a sociedade como locus político (no sentido de constituição do poder) que se diferencia do Estado, consistindo em uma associação de indivíduos tendo em vista a realização de interesses comuns ou interesses privados. No século XVIII, no contexto do assim chamado Iluminismo Escocês, veremos essa ideia se desenvolver a partir da introdução da economia como atividade fundadora da associação humana; no século seguinte, o conceito fará sua inscrição definitiva no campo da filosofia política e das ciências sociais a partir da distinção entre Estado e sociedade burguesa (Hegel), sem jamais perder a referência à esfera econômica (Marx). Como quer que seja, o conceito de sociedade civil denota a existência de uma zona intermediária entre o indivíduo e a sociedade, o que é conforme à definição arendtiana do social. Como afirma Adam B. Seligman:

Originalmente postulado no século XVIII como referindo-se ao domínio da mutualidade social, no século XIX ele foi usado para caracterizar aquele aspecto da existência social que existia para além do Estado (...) É o reino dos 'direitos', mas também da propriedade, da civilidade, mas também da exploração econômica. Ele repousa sobre o indivíduo legalmente livre, mas também sobre a comunidade dos indivíduos livres. Apartada do Estado, ela é, no entanto, regulada pela lei. Um domínio público, embora constituído por indivíduos privados (SELIGMAN, 1992, p. 03).

Malgrado a diferença entre as diversas concepções de sociedade civil, entre elas haverá o seguinte ponto comum: ela implica a relação problemática entre o público e o privado, o

\footnotetext{
${ }^{5}$ A respeito, ver seu livro John Locke et les fondements de la liberté moderne (2001).
} 
individual e o social, entre a ética do interesse público e os interesses individuais, entre as paixões particulares e as preocupações públicas. Ainda Seligman: "Pois se o sentido de um público partilhado é constitutivo da sociedade civil, também o é a existência do privado" (SELIGMAN, 1992, p. 05).

Olhando por esse prisma, Arendt tem razões de sobra para mostrar-se reticente à utilização do conceito. Afinal de contas, esta concepção parece muito próxima da definiçãa do social fornecida por ela, marcadamente pela sua natureza "híbrida", como lugar intermediário entre o público e o privado. E não poderíamos criticar Arendt em sua descrença no poder da sociedade civil operar a transformação do indivíduo privado em cidadão. De fato, quando nós recorremos a autores como Ferguson e Smith - sem desconsiderar suas diferenças - nos deparamos como uma teoria do social que se apoia sobre a ideia de mercado como principal agente transformador das relações intersubjetivas e fundador da comunidade humana. "A ideia de mercado, afirma Pierre Rosanvallon, constitui principalmente um tipo de modelo político alternativo" (ROSANVALLON, p. 2002, p. 10). Ora, estamos nos antípodas da teoria arendtiana, que vê na economia política a força despolitizadora das sociedades modernas.

Mas o ponto que nos interessa destacar é outro, isto é, o fato de que a sociedade civil descreve a força política da comunidade, independentemente da existência do aparato estatal. Em outras palavras, importa ressaltar a dimensão civil da sociedade, sua capacidade de mobilizar os indivíduos como cidadãos. Portanto, os interesses econômicos e privados estão longe de esgotar o sentido da sociedade civil. É isso que Locke já havia percebido, malgrado sua fama de arauto do individualismo burguês. Mas esse elemento que transcende o interesse privado, Locke o havia identificado com a lei de natureza, que se formula como uma injunção ética de raiz religiosa. Este, aliás, é o momento mais tomista (e calvinista) de Locke, como vemos na seguinte passagem do Segundo tratado:

Tendo Deus feito o homem uma criatura tal que, segundo seu próprio juízo, não lhe era conveniente estar só, colocou-o sob fortes obrigações de necessidade, conveniência e inclinação para conduzi-lo à sociedade, assim como o proveu de entendimento e linguagem para perpetuá-la e dela desfrutar (LOCKE, 1998, p. 451). 
Esta é para Locke a origem da sociedade civil, a qual tem de basear-se ainda sobre a capacidade humana de associar-se, de fazer contratos por meio do uso da linguagem. Ora, o destino do conceito de sociedade civil no século XVIII consistiu na substituição desse elemento transcendente por uma nova antropologia que centrava-se sobre a noção de sentimentos morais e de simpatia. Mas também, e sobretudo, na capacidade humana de fazer trocas, motivada pelos interesses privados. Em A condição humana, Arendt descreve, em parte, a sociedade a partir dessas últimas características, deixando de lado sua dimensão propriamente política. Tudo se passa como se a dimensão econômica do social (mas também outras de suas características, como o conformismo) neutralizasse por completo aos olhos de Arendt sua capacidade política. Entretanto, essa não será a única posição de Arendt sobre o assunto, pois em seu estudo sobre os processos revolucionários a dimensão política da sociedade é ressaltada, sob a égide das "comunidades"6.

\section{A Sociedade contra o Social I: A Revolução}

No outono de 1958, Arendt escreve o seguinte a respeito da Revolução Húngara:

A Revolução Húngara ensinou-me uma lição. Se nós levarmos em conta a espantosa emergência do sistema de conselhos durante a Revolução Húngara, então parece que somos confrontados com duas novas formas de governo em nosso tempo, ambas podendo ser entendidas apenas contra [o pano de fundo] da bancarrota do corpo político do Estado-nação (ARENDT, 2018, p. 159).

Alguns anos mais tarde, no livro dedicado à revolução, veremos que o ressurgimento do sistema de conselhos ocupará um lugar muito especial em sua compreensão das possibilidades políticas da modernidade. Afinal de contas, trata-se de uma "nova forma de governo", alternativa à forma tradicional que se apoiava sobre o sistema representativo dos partidos e, simultaneamente, trata-se de um novo "espaço de liberdade" (ARENDT, 1990, p. 264). Mas em que consistia exatamente essa "nova forma de governo", a não ser na participação dos cidadãos nos

\footnotetext{
${ }^{6}$ Parece ecoar nessa distinção a célebre diferenciação entre Gemeinschaft e Gesellschaft estabelecida por Ferdinand Tönnies no final do século XIX.
} 
afazeres públicos por meio de organizações locais, criadas espontaneamente durante o processo revolucionário? Certamente, a formação dos conselhos manifesta o desejo humano de ocupar-se das coisas políticas, eles dão vazão também ao desejo de imortalizar-se e asseguram a possibilidade de experimentar a chamada "felicidade pública". Mas o que nos interessa compreender é sobre qual experiência o sistema de conselhos se baseia. Ora, parece-me que Arendt, malgrado a natureza absolutamente espontânea dessas formações, acredita ser possível encontrar um antecedente importante naquelas comunidades políticas anteriores e independentes da formação do aparato estatal, precisamente aquilo que ela, na esteira de Thomas Jefferson, vai denominar de "repúblicas elementares". E o autor que lhe fornece as informações históricas a esse respeito é Alexis de Tocqueville, em especial, o primeiro volume de seu Democracia na América. Estas comunidades políticas pré-estatais são também "espaços de liberdade", são também lugares onde o poder emerge, e elas definem o quadro em que a capacidade política humana de estabelecer contratos é requisitada.

Tocqueville denomina essas formas de associação, presentes na América do Norte desde o período de sua colonização, de "sistema comunal". Segundo ele,

as instituições comunais estão para a liberdade assim como as escolas primárias estão para a ciência; elas a colocam ao alcance do povo; elas lhe fazem provar seu uso pacífico e o habituam a dela se servir (TOCQUEVILLE, 1981, p. 123).

Mas como exatamente essas “instituições” produzem esse benefício? Para Tocqueville, habituando o cidadão americano aos afazeres cívicos, de modo a produzir um "gosto maduro e refletido pela liberdade" (TOCQUEVILLE, 1981, p. 135). Mas para Arendt está sobretudo em jogo o fato de que essas comunidades atualizam a capacidade humana de agir com o outro, de fazer associações no momento crucial de fundação dos corpos políticos. Foi essa experiência que amadureceu os americanos para a revolução ${ }^{7}$; foi ela que os ensinou que o poder político

\footnotetext{
7 "This was the experience that guided the men of the Revolution; it had taught not only them but the people who had delegated and 'so betrusted' them, how to establish and found public bodies, and as such it was without parallel in any other part of the world" (ARENDT, 1990, p. 176).
} 
está no povo, abrindo a via para uma revolução cuja preocupação fosse essencialmente política, vale dizer, a fundação de um espaço para a liberdade. Ora, essa experiência é, como dito acima, uma experiência de poder, entendido não como uma força externa ao corpo político, mas justamente como aquilo que vem a existir a partir da reunião dos cidadãos em condição de igualdade.

Os homens da Revolução Americana (...) entenderam por poder o exato oposto de uma violência natural pré-política. Para eles, o poder veio a existir quando e onde o povo se reunia e se vinculava através de promessas, pactos e compromissos mútuos; apenas tal poder, que repousava sobre a reciprocidade e a mutualidade, era poder real e legítimo, enquanto o assim chamado poder dos reis ou príncipes ou aristocratas, porque não emergia de suas relações mútuas, mas, na melhor das hipóteses, repousava sobre o consenso, era espúrio e usurpado (ARENDT, 1990, p. 181).

É precisamente nesse ponto que Arendt pode retomar a tradição contratualista, pois que ela havia explicitado a natureza política dos pactos, quer dizer, sua capacidade de gerar poder. Mas ela lembra que há, no interior dessa tradição, uma distinção entre "pacto de associação" e "pacto de submissão". O pacto de submissão consiste na entrega do poder político a um terceiro e, por isso, introduz uma verticalidade, uma relação de dominação que é a negação mesma da política como participação. Em contrapartida, o pacto de associação pode ser caracterizado da seguinte maneira:

O contrato mútuo pelo qual as pessoas se vinculam de modo a formar uma comunidade está baseado na reciprocidade e pressupõe a igualdade; seu conteúdo atual é uma promessa e seu resultado é na verdade uma "sociedade" ou "associação" (cosociation) no antigo sentido romano de societas, que significa aliança. Tal aliança reúne a força isolada dos parceiros aliados e os vincula em uma nova estrutura de poder em virtude de "promessas livres e sinceras" (ARENDT, 1990, p. 170).

Não despontaria nessa passagem esse sentido plenamente político de sociedade? A referencia à societas romana não deixa lugar para dúvidas. Uma passagem de seu livro inacabado de introdução à política ajuda a esclarecer este ponto. Referindo-se aos aliados que os romanos conquistavam em suas campanhas militares e integravam em sua comunidade política, Arendt afirma o seguinte: 
Destes aliados de Roma, destes socii, quase todos antigos inimigos que foram conquistados, emergiu a societas, que nada tinha a ver com a sociedade, mas antes com uma comunidade cooperativa que promovia os relacionamentos entre parceiros (ARENDT, 2005, pp. 185-6).

A oposição, nessa passagem, entre societas e sociedade não deve nos enganar: Arendt está descrevendo justamente um dos traços salientes da sociedade civil, a saber, sua natureza associativa, vinculante, que mobiliza os seres humanos como parceiros, em condição de igualdade e orientados por um interesse comum. Além disso, essa associação não se assenta, em absoluto, em instituições pré-estabelecidas: elas passam a existir a partir do momento que os seres humanos colocam em prática sua capacidade de fazer promessas. Portanto, elas têm sua origem na própria ação humana.

Parece correto então sugerir uma correspondência entre a concepção arendtiana de "comunidade cooperativa" com aquele de sociedade civil, sem que se trate de uma completa identificação entre um e outro. Arendt continua recusando a presença no domínio público de interesses individuais como um elemento da política, mas ficam resguardadas em seu pensamento político a natureza pública, a força associativa e a capacidade auto-instituinte da sociedade civil. Ela continua fiel às suas críticas ao aparecimento da questão social na esfera pública, mas a descoberta de que o fenômeno revolucionário se assenta, em última instância, na capacidade humana de ação a obriga a colocar em primeiro plano o espaço associativo em que ela é efetivamente exercida.

\section{A Sociedade contra o Social 2: A Desobediência Civil}

O texto sobre a desobediência civil, publicado em Crises da república, tem fortes continuidades com seu livro sobre as revoluções. Em ambos os casos, está em questão examinar as potencialidades da ação no que concerne à transformação ou conservação do corpo político. Em ambos os casos, o desenrolar da ação implica uma relação com a Constituição, seja para recuperar seu espírito originário seja para, mais radicalmente, destituí-la em favor de um novo ordenamento jurídico. Não surpreende, então, encontrarmos no texto sobre a desobediência a 
evocação da teoria do contrato, uma nova referência a Locke e a mobilização da noção de "consentimento".

Servindo-se das mesmas referências históricas (em especial, a experiência pré-revolucionária americana), Arendt vai repisar o terreno antes explorado, mostrando agora que aquilo que confere legitimidade às iniciativas de resistência ao poder estabelecido por meio da desobediência é o respeito ao espírito originário que animava os americanos antes mesmo da fundação da república. Para explicitar a maneira como esse espírito ganhava corpo na história, Arendt evoca novamente a teoria do contrato "horizontal" formulada por Locke e escreve, quase com as mesmas palavras do livro sobre as revoluções, o seguinte:

A república americana, em contraste [com o contrato "vertical"], repousa sobre o poder do povo - a velha potestas in populo romana - e o poder confiado às autoridades é poder delegado, que pode ser revogado (...) A teoria do contrato original de Locke, que fez existir não o governo, mas a sociedade a palavra sendo entendida no sentido latino de societas, uma "aliança" entre todos membros individuais, que contratam com seu governo após terem contratado mutuamente entre eles - chamarei de versão horizontal do contrato social. Este contrato limita o poder de cada membro individual, mas deixa intacto o poder da sociedade; a sociedade então estabelece o governo "sobre o solo de um contrato original entre membros independentes e individuais" (ARENDT, 1972, p. 66) ${ }^{8}$.

Não é difícil perceber o quanto Arendt incorporou a linguagem de Locke, em especial, a ênfase sobre a noção de "consentimento" que presidirá toda a reflexão sobre o fenômeno da desobediência. 0 contrato implica uma forma de consentimento, mas, afirma Arendt, trata-se de um "consentimento ativo" que ao contrário de dispensar os cidadãos dos afazeres cívicos instiga seu interesse pelos assuntos públicos. Uma das formas de reativação desse consentimento é precisamente a desobediência civil diante de uma lei que fere os princípios que animam a Constituição ou diante da negligência com estes mesmo princípios da parte das autoridades em ofício. Nesse sentido, a desobediência civil necessariamente evoca o momento fundador do corpo político. Mas faz mais do que isso. Ela indica precisamente o descolamento

\footnotetext{
${ }^{8}$ A citação no final da frase é de John Adams.
} 
entre o poder estabelecido e a sociedade que o originou. Por fim, Arendt assume plenamente o modelo lockeano da resistência e da limitação da soberania:

Na visão de Locke, isto [Arendt está se referindo à formação da sociedade por meio da promessa] significa que a sociedade permanece intacta mesmo se "o governo é dissolvido" ou quebra seu acordo com a sociedade, se transformando em tirania. Uma vez estabelecida, a sociedade, enquanto existir, jamais pode ser lançada de volta à ausência de leis e à anarquia do estado de natureza. Nas palavras de Locke, "o poder que todo indivíduo deu à sociedade, quando nela ingressou, jamais poderá voltar ao indivíduo novamente, enquanto a sociedade durar, mas sempre permanecerá na comunidade". Esta é de fato uma nova versão da velha potestas in populo, pois a consequência é que, em contraste com as teorias anteriores do direito de resistência, segundo as quais o povo poderia agir apenas "quando as correntes estão colocadas", ele agora tem o direito, novamente nas palavras de Locke, de "impedir o acorrentamento". Quando os signatários da Declaração de Independência "mutuamente comprometeram" suas vidas, suas fortunas, e sua honra sagrada, eles estavam pensando nesse veio de experiências especificamente americano, assim como em termos de uma generalização e conceitualização dessas experiências por Locke (ARENDT, 1972, p. 87).

A passagem não pode deixar de surpreender. Locke parece emprestar sua voz para Arendt expressar sua própria concepção dos fundamentos da vida republicana, tendo antes feito o mesmo com os pais fundadores. Obviamente, seria possível contestar aqui a fidelidade histórica dessa filiação. Nada seria menos interessante. 0 que realmente interessa é o fato de a concepção lockeana de sociedade civil ter sido finalmente absorvida por Arendt, inteiramente desvinculada da dimensão "econômica" que determinava o "social”. Mais uma vez, cabe observar que o fenômeno político em tela, a saber, a desobediência civil, torna necessária a evocação da sociedade civil como lugar de geração do poder claramente separada da instância estatal. Essa comunidade novamente é restituída quando os cidadãos, juntos, colocam em xeque o poder instituído e agem de modo a alterar ou proteger o sistema de leis sem os quais nenhuma república pode existir. A sociedade civil se mobiliza em momentos de crise, momentos nos quais torna-se necessário referir o poder a sua fonte e recuperar sua natureza criativa ou conservadora. Se é realmente isso que Arendt tem em mente em sua utilização de Locke, então podemos dizer que ela encontra um lugar importante em sua reflexão para o conceito de sociedade civil. 


\section{Considerações Finais}

Meu objetivo consistiu em mostrar como no interior de seu percurso reflexivo Hannah Arendt terminou por conceder lugar ao conceito de sociedade civil, o que deveria nos levar a considerar de maneira mais nuançada sua célebre separação entre o político e o social. Certamente, ela permanece coerente com a dura crítica ao "social” presente em A condição humana. Ela jamais abandonará a convicção de que a "economia política", a moralidade social, o ímpeto conformista, são essencialmente contrários ao espírito público, à política participativa e ao verdadeiro exercício da liberdade. Mas o "social" não é a sociedade. Sem jamais ter se dado ao trabalho de fazer essa distinção, Arendt descobriu, em sua análise do fenômeno revolucionário e, mais tarde, em sua reflexão sobre a desobediência civil, a necessidade de lançar mão de um conceito de sociedade que tem afinidades evidentes com aquilo que John Locke chamou de "sociedade civil". Afinal de contas, como compreender a experiência de dissolução do governo em termos políticos sem evocar a ideia de uma forma prévia de sociabilidade? 0 que Arendt recusa é a chantagem (que remonta a Hobbes) que nos obriga a escolher entre o poder do Estado ou o estado de natureza. Segundo ela, esse foi um dos erros dos revolucionários jacobinos, que não viam outra opção para a ameaça de retorno à vida selvagem além do reforço do poder instituído. A esfera política, como vemos no caso da revolução e no caso da desobediência, isto é, diante do desmoronamento ou do esvaziamento das estruturas de poder, implica desde sempre a capacidade de associação. Ela não lhe é atribuída por nenhum elemento extra-político, nem precisamos ressuscitar a noção de lei natural para compreender essa relação. A ação, dizia Arendt em A condição humana, é a única atividade que se realiza exclusivamente entre os homens, portanto, no mundo. E porque onde os seres humanos se relacionam existe um mundo, onde eles agem juntos se constitui uma forma de sociedade?.

Para encerrar, gostaria apenas de fazer um último apontamento: a utilização do vocabulário de Locke e a presença de uma concepção de sociedade civil não explicitada em seus textos

\footnotetext{
${ }^{9}$ E, uma vez que referi-me ao mundo, valeria a pena lembrar, com Senem Yildirim, que "a pluralidade é outra característica da sociedade civil" (YILDIRIM, 2014, p. 876).
} 
não obriga, em absoluto, a considerar Hannah Arendt uma pensadora de estirpe liberal. Em primeiro lugar, identificar o conceito de sociedade civil com liberalismo é um equívoco conceitual. 0 termo comporta um sentido político muito mais robusto, como quis mostrar. Na verdade, acho que poderíamos pensar o contrário: a sociedade civil, como vemos em Arendt, está vinculada à ideia de "consentimento ativo", à noção de participação política e espírito cívico, as quais têm muito mais afinidade com a tradição republicana. Mas além disso, o sentido mais profundo de sociedade civil é decifrado apenas quando a entendemos no contexto da ação. Aí ela revela a insuficiência de uma concepção do social purificada da política. E não seria essa a mitificação produzida liberalismo?

\section{Referências bibliográficas}

ARENDT, H. The Human condition. Chicago: The University of Chicago Press, 1958.

ARENDT, H. Civil Disobedience. In: Crises of the republic. San Diego, Nova York, Londres: A Harvest Book/Harcourt Brace \& Company, 1972.

ARENDT, H. On revolution. Nova York: Penguin, 1990 (2a. edição).

ARENDT, H. Introduction into Politics. In: The promise of politics. Nova York: Schocken Books, 2005.

ARENDT, H. Totalitarianism. In: Thinking without a banister. Nova York: Schocken Books, 2018.

BENHABIB, S. The reluctant modernism of Hannah Arendt. Londres: Rowman \& Littlefield Publishers, 2003.

CORREIA, A. A Questão Social em Hannah Arendt: Apontamentos Críticos. In: Revista de Filosofia Aurora, vol. 20, n. 26, 2008, pp. 101-12.

LOCKE, J. Segundo tratado sobre o governo. In: Dois tratados sobre o governo. Trad. de Júlio Fischer. São Paulo: Martins Fontes, 1998.

PITKIN, H. F. The attack of the blob. Hannah Arendt's concept of the social. Chicago: The University of Chicago Press, 1998.

ROSANVALlON, P. o liberalismo econômico. História da ideia de mercado. Trad. de Antônio Penalves Rocha. Baurú: EDUSC, 2002.

SELIGMAN, A. B. The idea of civil society. Nova York: The Free Press, 1992.

SPITZ, J. F. John Locke et les fondements de la liberté moderne. Paris: PUF, 2001.

TOCQUEVILLE, A. de. De la démocratie en Amérique 1. Paris: Flammarion, 1981.

YILDIRIM, S. Arendt's Promise to Civil Society: Bridging the Social and the Political. In: The European Legacy, vol. 19, no. 07, 2014, pp. 869-882. 


\section{Helton Adverse}

Doutor em Filosofia pela UFMG (2003). Professor Titular do Departamento de Filosofia da UFMG. Tem experiência na área de Filosofia, com ênfase em Filosofia Política Moderna e do Renascimento e História da Filosofia. Mais recentemente, tem realizado pesquisas sobre autores modernos e contemporâneos como Maquiavel, Hobbes, Rousseau, Foucault e Hannah Arendt. 